\title{
Are Indian Organizations Disabled Friendly? - Inclusive Talent Acquisition Function for Indian Organizations
}

\author{
Mita Mehta, Ranu Kumari, Komal Sharma, Arti Chandani
}

\begin{abstract}
This study aims to understand whether Indian Organizations have disabled-friendly work environment or not. Study also aims to understand the acceptability of disabled workforce among the Indian Organization. Finally, research recommends various practices and policies for aiding Indian organizations to create a disabled-friendly environment. This study aims at studying disability as diversity inclusion as a talent acquisition tool. This study has adopted the mixed method approach as a research methodology. Quantitative methodology to understand the present status of disabled workforce in India. Under qualitative study, interview Employees and Human Resource (HR) Managers as well as Non-Governmental Organizations (NGOs) - dealing with disabled peoplerepresentatives were conducted to understand the talent acquisition function and its inclusive approach. Findings of this study suggests ways through which inclusive work culture can be promoted in Indian Organization. Analysis of quantities and qualitative research reveals that Indian organizations have to go long way in engaging disabled employees at workplace. NGOs also reveals that even if talent acquisition functions looks inclusive but in reality it is not. Organizations should offer positions to disabled at all levels rather than at lower level. It will also contribute to an emerging conceptual framework on employment integration of people with disability and the role of employers within this framework. This study will guide Indian hiring agents to make talent acquisition a truly inclusive one. Such study has not been yet done in Indian organization, and it will be a guiding tool for talent acquisition managers as well as other researchers in this area.
\end{abstract} Acquisition, Opportunity

\section{INTRODUCTION}

Diversity inclusion drive has started as one of the policies which drive today's Human Resource Managers and corporate all over the world. In India, disabled in the workforce has declined drastically to $38 \%$ from $41 \%$ in the last few years; despite the country's economic growth. This study attempts to check the present status of employment and acceptability of Person with Disability (PWD) in India. 'Diversity' was devised in the United States post-1980's and spread across the world. In the last few years; the organizations have encompassed it by realizing the strong linkages between the inclusion of diversity and business

Revised Manuscript Received on 14 September, 2019.

Dr. Mita Mehta Associate Professor, Symbiosis Institute of Management Studies, Symbiosis International (Deemed University), Range Hill, Pune, India , mita.mehta@sims.edu

Ranu Kumari, Founder \& Managing Partner ,Latitudebox, Bangalore, Indiaranupnkj@gmail.com

Komal Sharma,Talent Acquisition specialist, GoScale technologies, Bangalore, India, komals601@ gmail.com

Dr. Arti Chandani, Associate Professor, Symbiosis Institute of Management Studies, Symbiosis International (Deemed University), Range Hill, Pune, India arti.chandani@ sims.edu
Keywords: Disabled-friendly, Indian Organizations, Talent

competitive advantage. The concept initially started as an edge to provide equal employment and later decoded into a comprehensive industry-wide policy of diversity. As per statistics produced by International Labour Organization in 2011 reveals that $73.6 \%$ of the disabled population in India are still not engaged the labor force. Of these, those with a mental disability, disabled women and those in rural areas are the worst neglected. At present, there are around 2.68 crore disabled people in India [1] out of which only $36.3 \%$ of disabled people are engaged in work. As per the report, the average employment rate of disabled people is $0.28 \%$ in the private sector and $0.54 \%$ in the public sector. The ratio of the person engaged in the unorganized workforce to organized is very high. More than $87 \%$ of the disabled are in the unorganized sector.

It is estimated that the total number of the person with a disability will be around 10 million by 2022 which is a huge chunk of human capital and ignoring this will lead into a loss of about 5-7\% of GDP [1]. Very few rather, a handful of organizations have shown positive work culture and hiring strategies for PWD. While several others still have apprehensions and doubts that avert them from tapping into this vast pool of resources. The shortage of pensiveness and awareness has been one of the significant hurdles in encouraging employment opportunities for people with disabilities.

It has been observed that many times, Disability is looked up as a medical or charity model rather than a thoughtful one. Indian organizations' have not yet been able to see disability as a part of human diversity. It has been observed over the years that PWD is seen with pity or charity issue, and unless we come out from this mental stigma, it would become very difficult for India organizations to tap this as one of the talents. Many organizations though empathetic about disabled people in India, [2] yet do not want to put their organizations at risk by inviting a unique and different set of the workforce at the workplace.

There have been some pre-conceived notions around disability like- a person with a disability would not be able to tolerate the pressure of a job. Also, it would be costly to hire a person with a disability; it will affect productivity, etc.

These myths can only be addressed by creating awareness and sensitivity among organizations.

Research method planned in this paper makes it possible to evaluate employers' perceptions of employing workers with a disability. Findings presented in this paper will help 

FOR INDIAN ORGANIZATIONS

in developing and supporting kinds of resources. Employers need to promote an inclusive workplace [3].

\section{MEANING OF THE TERMS \& METHODOLOGY}

\section{A. Disability}

If we try to understand the conceptual point here, we will find that disability has no universal definition. Every other nation has its legal definition of disability. According to the World Health Organization: (WHO) 'Disability is big term which includes impairments, functional limitations as well as restrictions. An impairment is an imitation in physical body function or structure; a functional limitation is problem which an individual encounters while carrying out any activity -while a participation restriction is a difficulty experienced by an individual in involvement in life situations' [4]. While in the Indian context "person with a disability" can be understood as person with mental, physical, intellectual or sensory impairment which, restricts him or her in participating at fullest level unlike other normal individuals. Prior PWD (Person with Disability) Act, 1995 characterized disabilities into seven classes, which got stretched to twenty-one classifications in RPWD (Rights of Person with Disability Act 2016). There were numerous new categories like acid assault victims, sickle cell disease, dwarfism, and so forth. In the Indian context, one cannot find many classes of disability in the listed categories, but the Central Government once determines these categories will be incorporated. According to RPWD, if we have to consider people for reservation in government associations, then the benchmark disability should be at least $40 \%$. Also, the benefits for the disabled can only be availed if the person has a certificate from the appropriate authority. Disability is a condition that varies in degrees from person to person. Impairment cannot be termed as a static condition. The state has elements of dependency, and at times, degrees of limitations.

Disability Rights Specialist at United Nations India shares, "Disability is looked up as a medical or charity model. We have not been able to see disability as a part of human diversity. We need to see disability as a human or social issue and not a charity issue." She added, "We already have pre-conceived notions around disability like- a person with a disability would not be able to withstand the pressure of a job, it would be expensive to hire a person with a disability, it will affect the productivity, etc. These myths can only be addressed by creating awareness and sensitivity among organizations.

\section{B. Talent Acquisition}

Talent Acquisition as a first step to identify disabled people as sourcing itself will be a big step. In this study, researchers have tried to correlate it with an opportunity that the organization will offer to the person with a disability and thereby offering the chance to be part of the workforce. This can be included either as a part of the external source or as an internal source. It can also be offered as a strategy while hiring candidates from an internal referral, and this will boost the morale of present candidates also. So talent acquisition is the most suitable way of recommending the disabled workforce to the workplace.

\section{MODELS OF DISABILITY}

Dealing with a disability can be very challenging, and four models attempt to deal with it. The first model is the Charity Model, that depends on the pitying misfortune of others which is based on the assumption that disability makes people powerless to some extent and somewhat dependent on others for their daily routine or even emotional being at times. This, at times, becomes so prevalent that the people with disability themselves fortify this idea and end up doing pitying themselves. The second model is the Medical Model that depends on the presumption that the state of disability is not a 'typical' state to be in and hence, should to be cured. The third model is the Social Model is one model where physical, institutional, or attitudinal social hindrances come into the picture and are assumed to cause disability in a person. Further, the last model, called Rightsbased Model identifies the rights of the disabled as a fundamental human right. This model endeavors to strengthen the disabled individual and ensure full participation from them. RPWD, 2016, the earlier PWD Act, which was more slanted to the Medical Model, is inclined more towards the Social and Right based model.

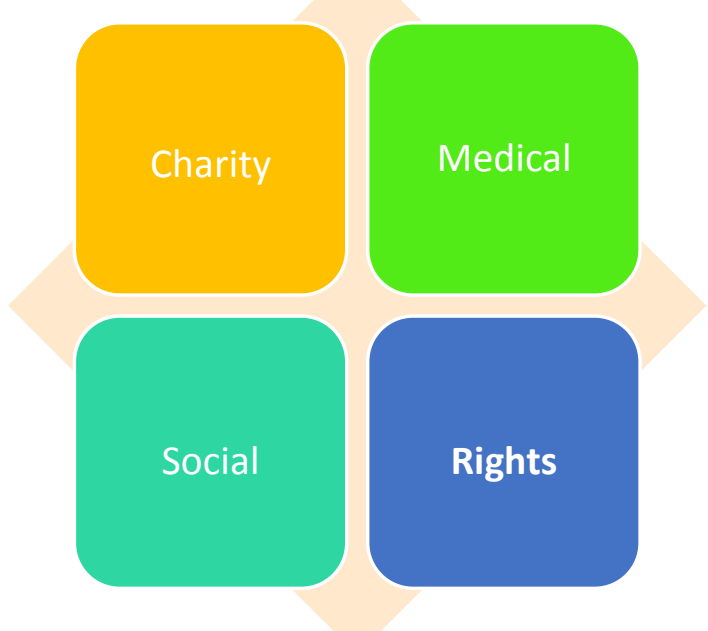

Figure 1. Models of Disability

\section{OBJECTIVES OF THE STUDY}

This study aims at identifying the status of disabled people in India through extensive literature review, secondary data along with primary data on the interaction between employment integration and retaining of people diagnosed with a disability in the Indian organization with following detail objectives;

1. To understand the present status of employment and acceptability of the disabled in India.

2. To understand if Indian Organizations have disabled-friendly work environment.

3. To recommend various practices and policies for aiding Indian organizations - to guide talent acquisition function across the Indian corporate sector. 


\section{REVIEW OF LITERATURE}

While reviewing literature authors confirms that there is a significant number of Indians having disabilities of one form or the other. The Rights of Persons with Disabilities Act (RPWD), 2016, which is quite recent in India, has been enacted to make both public and private sector organizations responsible for ensuring disability-friendly workplaces [5].Also concluded that disability is a way of life, and roles of both private and public sector organizations are critical in mainstreaming disability-related issues. Going beyond legal compliance, Indian organizations can strive to work in many areas to make the organization accommodative of all forms of abilities [5]. It was emphasized that issues like underrepresentation and job segregation are specially articulated for individuals with disabilities, who display among the highest unemployment rates of any population [6]. Persons who have learning disabilities would value a workforce with an optimistic attitude, with staff who are expert in assisting people to improvement independence and have a voice [7]. In literature authors also found that creamskimming, i.e., picking most able candidates by program organizers, is indeed in practice as companies end up recruiting individuals without disabilities. And, while hiring, individuals with psychic disabilities are preferred over some disability groups [8].Some disabled people confront rejection from hiring agents on the excuses that have little to do with the ability to perform the fundamental functions of particular jobs while others confront exploitation in market discipline in public and non-profit organizations limit their capacity to adjust disabled workers. Sometimes disabled persons have experienced bulling also at workplace [10]. To have a supportive employer is often a matter of trial and error, and this may be aggravated by the growth of short-term contract work [11]. This is also because some employers continue to conceptualize disabled people as unemployable Physical infrastructure and social team of the workplaces, and the extent to which employers are directed to provide facility play a major role in shaping the value of citizenship for disabled people in the labor market. Accessible infrastructure requires sustained pressure for legislation mandating accommodation by for-profit employers.

Most of the research done in this field suggest that employers are not too keen on hiring and retaining persons with disabilities. This practice emerges from their belief system. For Example, they think such employees' job performance keeps declining because of their disability, and they have inaccurate knowledge about accommodations and expenses for the same, and concerns about legal liability also influences their beliefs [12]; All this leads to people not disclosing their disability [13]. Also it is a very personal decision for a person with a disability not to disclose the same to a potential or current employer.

Disability disclosure, on the one hand, can assure that representatives get suitable work environment, and can help many corporate to respond all the more viably to diversity and inclusion goal of increasing the acquisition and retention of individuals with disabilities. Then again, exposure may likewise bring about undesirable employment magnitudes for employees, such as lowered supervisor relegated service occupations[9]. Also, funding cuts and

expectations, seclusion from colleagues, and improved probability of cessation [13]. Employers believe that the focus shouldn't be only locating employment for persons with disabilities, but the main focus should be on resolving issues faced by such a workforce. Regrettably, very less information exists about employers' discernments and concerns about hiring people with disabilities [14]. Human resources' policy and actions should be matching with the needs of all employee groups, which includes employees with disabilities. Flexibility in job provisions and integrated programs are very important for social inclusion and should be followed by unconditional recruiting, open-minded performance assessment and promotion schemes, and fulfilling training needs for all employee groups [15]. Disabled people experience number of obstacles while in employment and it is also mentioned that accessible environment results into successful employment [16]. Employers, themselves claimed that disabled workforce are satisfied with the given task. Also, employees with disabilities feel encouraged when the organizations are ready and able to restructure job design contributing to creating an apt environment for them [17]. In leveraging an organization's reputable image and marketing programs through WOM, hiring of disabled frontline employees may play a major role [18]. Most of non-working people with disabilities reported their condition as an employment barrier that could be addressed with accommodations, such as lack of transportation or inaccessible workplace [19].

\section{RESEARCH GAP}

Based on the extensive literature review of more than 15 years we have learned that there has not been any integrated quality study which has been carried out for inclusive talent acquisition model considering disabled as a prime factor for diversity. There has been literature or factor affecting their unemployment, but no detail studies have been done specifically with respect to Indian organization. That is the main reason researchers have come up with this unique idea of carrying out detail study of the level of employment to inclusive talent acquisition strategy for the person with disability across Indian Organization.

\section{A. Research Questions}

1. Are Indian organizations fit for disabled employees?

2. Has Indian Organisation adopted a systematic strategy to include disabled employee as a part of their hiring process?

3. What will be the ways through which the Indian workplace will be inclusive?

\section{RESEARCH METHODOLOGY}

To identify the employability among disabled Indian people, this research has followed a mixed method to attain its objectives which are:

1. To understand the present status of employment and acceptability of the disabled in India. 
2. To understand if Indian Organizations have disabledfriendly work environment.

3. To recommend various practices and policies for aiding Indian organizations - to guide talent acquisition function across the Indian corporate sector - Finding and recommendation

Following research methodology under qualitative and quantitative method has been adopted to attend the above objectives. Researchers have used stratified random sampling for quantitative analysis, and thereby qualitative sampling was used to arrive at nested sampling.

\section{DATA ANALYSIS AND RESULTS}

A. Present status of employment and acceptability of disabled in India

1. Firstly, we have taken a total population parameter to understand human capital strength among disabled in India

Table- I: Total population of disabled and type of disability

\begin{tabular}{|l|l|l|}
\hline Particular & Numbers & Percentage \\
\hline Total Population & $1,028,610,328$ & 100 \\
\hline Disabled population & $21,906,769$ & $2.1 \%$ \\
\hline $\begin{array}{l}\text { Seeing disability (out of } \\
\text { disabled population) }\end{array}$ & $10,634,881$ & $1 \%$ \\
\hline Speech disability & $1,640,868$ & $0.2 \%$ \\
\hline Hearing disability & $1,261,722$ & $0.1 \%$ \\
\hline Movement disability & $6,105,477$ & $0.6 \%$ \\
\hline Mental disability & $2,263,821$ & $0.2 \%$ \\
\hline
\end{tabular}

Above mentions the disabled population as per census report, 2011 reflects the amount of human capital, which can be utilized as talent pool by most of the Indian organizations.

2. Out of these $21,906,769$ disabled, around $40 \%$ of disabled are going to be in the age bracket of 30 to 40 by 2020.

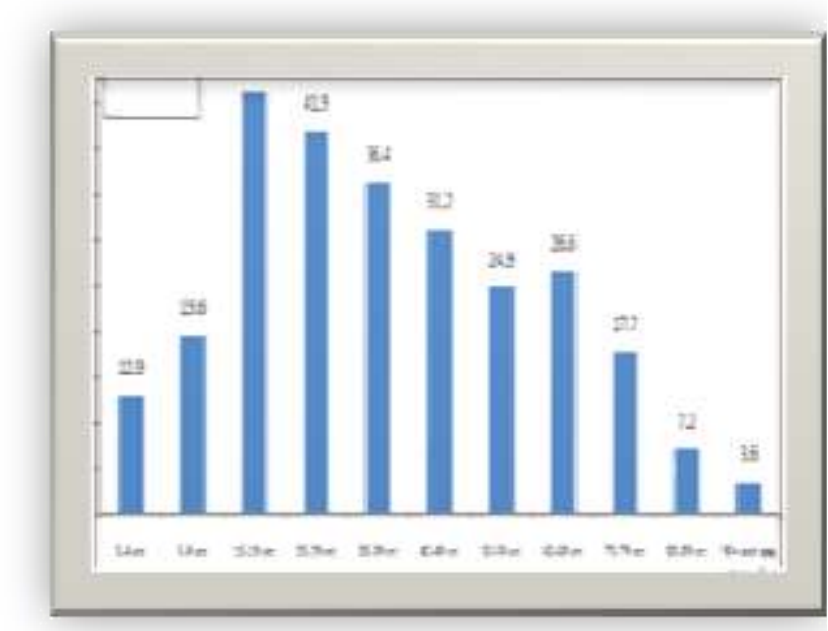

Figure 2: Disabled Population by age group in India as per census report 2011
Above chart depicts the age-wise analytics of the disabled population in India. It is derived that around $35 \%$ of the disabled population will be in the age bracket of 28 to 45 years by 2020 , which is a magnificent number for any talent pool.

3. Distribution of work status by disabled people in India

Among the disabled people those who are in some of the other workforces, the majority of them are in the agricultural sector. For the enablement of the disabled population, the completion of education and involvement in economic activity are tremendously important. The Census 2011 emphasized that nearly one-third of the total disabled persons are engaged in workforce. At National level total $36 \%$ of disabled are working, and the majority of them are either in the household or agricultural sector. Out of this, the female workers' ratio is quite less.

Distribution of disabled persons (in \%) by work status in India - Census, 2011

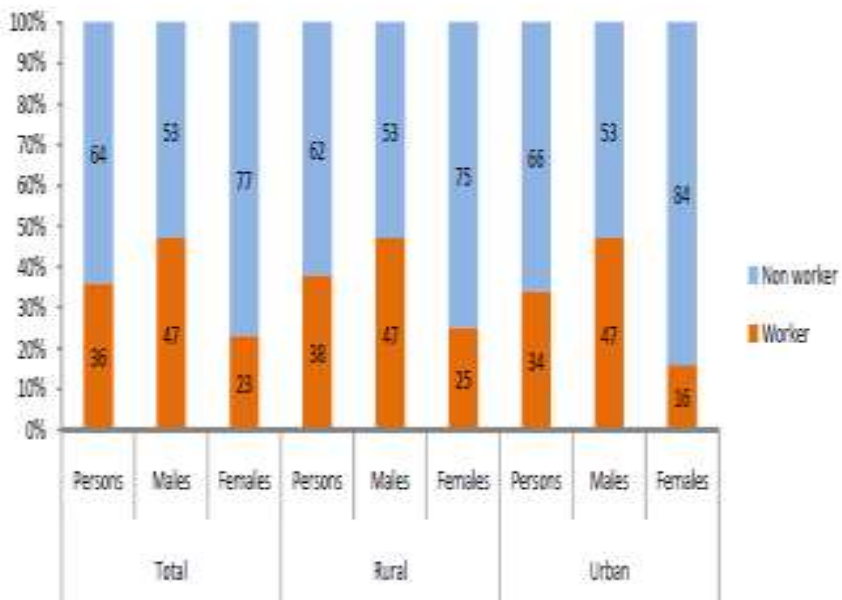

Figure 3 Distribution of disabled persons in work

Majority of the disabled population non-workers are depended and do not earn their livelihood on their own. This is where the major gaps are lying. Imagine a country where the majority of the population has been underutilized in skills or semi-skilled set-up is ignoring a major segment of its population in getting them engaged in the workforce.

B. To understand if Indian Organizations have disabledfriendly work environment.

For this objective researchers have used qualitative research along with quantitative (sampling) technique. This has been further classified into stratified random (nonprobability) sampling where;

Employees of various organizations have been interviewed in person as well as telephonically out of which 10 percent of employees were disabled (30)

a. HR executives have been interviewed along with coding and transcript of their interview excerpt (10)

b. NGOs representatives (6) dealing with disabled people have been interviewed to get more insight about the status 
A .Out of 30 employees interviewed around three individuals had a different set of disability.

- Status of disability among the focused group.

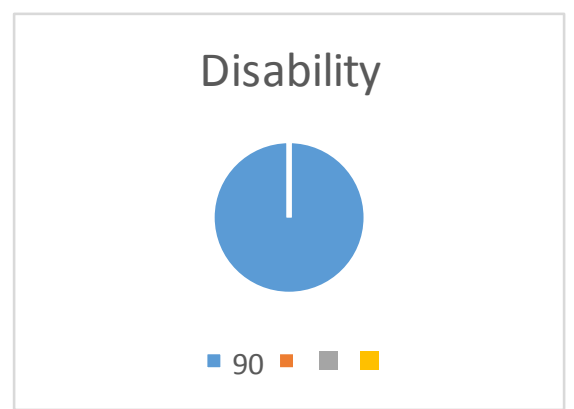

Figure 4 Status of Disability

- Are you getting the benefit of any disability reservation in your organization?

All $100 \%$ of respondent denied the fact that they are getting reservation benefit out of disability in an organization. It means their organizations have explicitly not cited a disabled candidate's reservation in their HR manual.

- Is your organization disabled friendly?

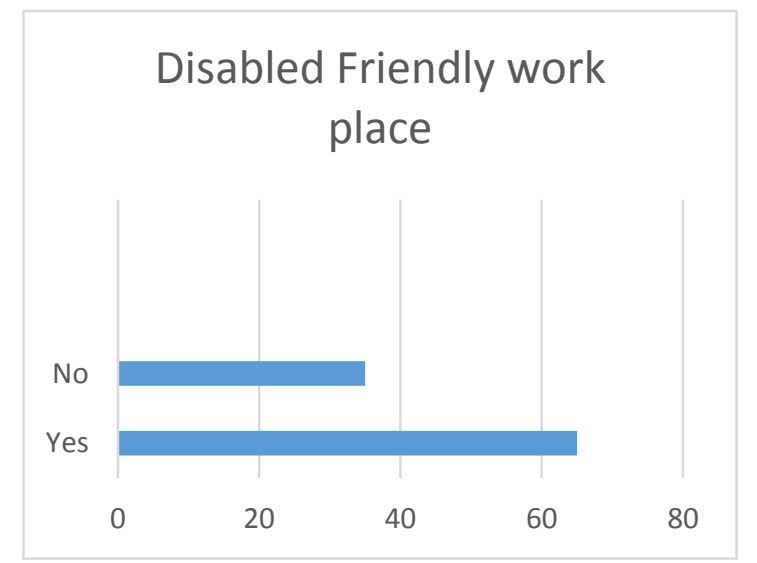

Figure 5 Disabled friendly organizations

Out of 30 candidates, $65 \%$ employee responded that they had a disabled-friendly workplace, but they do not have inclusive work policies. In further questions leading to disabled-friendly work culture similar $65 \%$ rated their organization on the scale of 3 to 4 , which means around $70 \%$ disabled-friendly.

- Further interaction with participants who are disabled was asked whether they face any challenges at the workplace being differently-abled; those who were differently-abled responded yes.

- We also interacted in terms of does their organization provides time flexibility to differently disabled, and we got a disappointing answer stating 'No'.

- Further on interaction which asked participants about how your career-related decisions get affected due to disability, and the majority of them responded their organization are not transparent in such issues.

- They have been asked to mention whether their supervisor is supportive enough to support as a mentor to any disabled employee where this was supposed to be answered based on their experience or observation. $87.1 \%$ responded they have conducive supervisors at the workplace in terms of helping and assisting disabled.

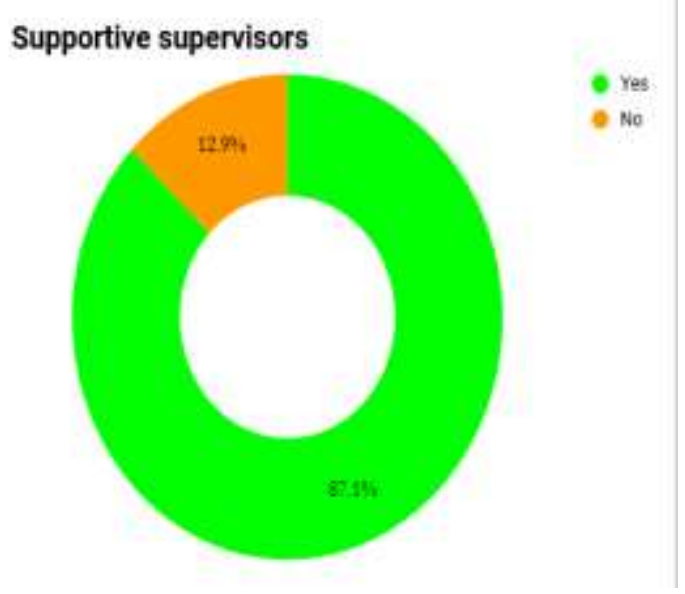

Figure 6 Supportive supervisors

- Participants were also questioned about does your employer made concerted efforts to make workplace disabled friendly, where the respondents replied yes they do observe efforts as part of either compliances or organizations initiated efforts but things are changing.

B Human Resource Executives were interviewed to understand their perspective on the inclusive work culture and the importance of bringing disability as a part of their talent acquisition function while some HR heads have accepted the potential that disabled people can bring to the table. While around four of them have several concerns and doubts that avert them from tapping into this vast pool of resources. Lack of sensitivity and awareness has been one of the most significant hurdles in promoting employment opportunities for people with disabilities.

a. While interacting with NGOs, interesting findings were gathered that society and organizations do accept that person with a disability has potentials, but it merely transforms into productive or constructive goal or efforts. Majority of them said that organizations are willing to hire a few of the disabled, but they would not offer them significant-high positions in organizations. This is because they are also under the stereotype mentality of career advancement is always call for the concept of FIT.

\section{DISCUSSION \& RESULTS}

Our study reveals that "Disability" is still looked up at the majority of the workplace as a medical or charity model. Indian organizations and employers are still not able to see disability as part of human diversity. They should see disability as a human or social [20] issue and not a charity issue. It has been derived from the interview of supervisors' / HR head that they have pre-conceived notions around disability like- a person with a disability would not be able to bear the pressure of a job, it would be costly to hire a person with a disability [21], it will affect the productivity, etc. These myths can only be addressed by creating awareness and sensitivity among organizations. Even negotiation in form of union representative is also seldom [22]. 

FOR INDIAN ORGANIZATIONS

\section{Future Scope}

The study has a lot of potentials to be carried out as a quantitative analysis with a more detailed questionnaire with a statistical tool. There can be an inter-state comparison of disabled people in India and their employment status in India.

\section{CONCLUSION AND SUGGESTIONS}

Following are the suggestions to make the Indian workplace more inclusive.

\section{Leadership Buy-in:}

Leaders play an influential role in getting any change in the organization. To build a plan around hiring persons with disability and also making it a practice, there is a need first to change the mindset of leaders. Entrenching inclusion at the workplace is inescapable for embracing the power of diversity. There has to be top to down approach when it comes to bringing diversity at the workplace. Leaders have to convince themselves the significance of bringing diversity at workplace and should create awareness among organizations

\section{Job and Work Analysis:}

There has been continuously resistance from employers in terms of concluding that disabled people are not capable of carrying out all types of work in an organization, and they need a particular job description which is not so. This does not give PWD to demonstrate his skill set and show the results. Organizations should have extensive job analysis which clearly defines that carrying out a particular job doesn't need extraordinary skills set.

\section{Sourcing Portals:}

Absence of skilled and unqualified proportion of candidates with a disability is comparatively high and therefore, finding the right aspirant for the right job becomes difficult for HR professionals. In the course of our research and various interviews, we found that NGOs are the most sought-after options when it comes to employing people with disabilities.

In the course of our research, it was also brought into notice about various online job portals like disabilityjobs.gov.in, Jobability.org, etc. that matches job enquirers from people with disabilities with job vacancies, placements, and resources.

\section{Accessible Environment:}

Organizations should get their infrastructure audited once in two years in terms of are they accessible to disabled. So what they are willing to hire people but what if their infrastructure is not accessible then it cannot be termed as an inclusive workplace.

According to the Confederation of Indian Industry (CII), an accessible environment includes:

- Equal opportunity policy and management

- Physical environment

- Information and Communication

- Safety and Emergency Evacuation

The work setting and work structure need to be accessible to all employees. Mobility and transport services, clients and customers, safety measures, physical access to buildings, washrooms, and disability-friendly two-way communications, etc. contributes to making a company genuinely inclusive [23] From the study, we conducted, we have found that Indian organizations have developed certain patterns when it comes to hiring a candidate for a certain kind of jobs in organizations. There is a high level of apprehensions prevailing in Indian organizations while hiring PWD at the workplace. Though supportive supervisors or conducive workplaces are positive signs for welcoming disabled candidates are the workplace, but that is not the end of the story. We do run a lot of campaign to make our society and infrastructure accessible, but we never forget that whether our workplaces are accessible or not. It has also been observed that it is not government only which is responsible for hiring and maintain disabled at public sector units, but it is also the responsibility of private and other regulatory bodies to govern this important mandate to ensure disabled people get an equal opportunity like any other normal candidate. It has been observed with many of the corporate sectors hiring disabled that they are able to manage the diverse needs of their customers when they bring diverse workplace from their side. It is not only inclusion at entry-level, but our research also throws light on what if a disabled person gets a chance for his or her career advancement like any other normal person. It becomes the duty of not only NGOs (Non-Governmental Organizations) but all HR executives to identify the ways in which this problem or issue can be sorted out by being visual and getting the support of their top management in identifying it as part of their strategic human resource strategy.

\section{REFERENCES}

1. Disability/Handicap - Census 2011. (n.d.). Retrieved $\begin{array}{lll}\text { February } & 11, \quad 2019, \quad \text { from }\end{array}$ https://www.census2011.co.in/disability.php

2. Meena, K., \& Vanka, S. (2013). Diversity Management and Human Resource Development-A Study of Indian Organizations. Pacific Business Review International, 5(7), 45-51. Retrieved from http://www.pbr.co.in/2013/2013_month/January/7.pdf

3. Khalema, N. E., \& Shankar, J. (2014). Perspectives on Employment Integration, Mental Illness and Disability, and Workplace Health. Advances in Public Health, 2014, 1-7. https://doi.org/10.1155/2014/258614

4. Disabilities. (2017, October 5). Retrieved December 20, 2018, from https://www.who.int/topics/disabilities/en

5. Sarkar, A. (2018). RPWD Act, 2016: Fostering a Disability-friendly Workplace in Indian Organizations. Indian Journal of Industrial Relations, 53(4), 591

6. Fassinger, R. E. (2008). Workplace diversity and public policy: Challenges and opportunities for psychology. American Psychologist, 63(4), 252-268. https://doi.org/10.1037/0003-066x.63.4.252

7. Davies, J., \& Matuska, G. (2018). Workforce development: perspectives from people with learning disabilities. Tizard Learning Disability Review, 23(4), 165172.https://doi.org/10.1108/TLDR-04-2017-0018 
8. Skedinger, P., \& Widerstedt, B. (2007). Cream skimming in employment programmes for the disabled? Evidence from Sweden. International Journal of Manpower, 28(8), 694-714 https://doi.org/10.1108/01437720710835174

9. Wilton, R., \& Schuer, S. (2006). Towards socio-spatial inclusion? Disabled people, neoliberalism and the contemporary labour market. Area,38(2),186-195. https://doi.org/10.1111/j.1475-4762.2006.00668.x

10. Vickers, M. H. (2014). Telling Tales to Share Multiple Truths: Disability and Workplace Bullying -- A SemiFiction Case Study. Employee Responsibilities and Rights Journal, 27(1), 27-45. https://doi.org/10.1007/s10672-014-9246-1

11. Bishop, D. V. (2002). Motor immaturity and specific speech and language impairment: Evidence for a common genetic basis. American Journal of Medical Genetics, 114(1), 56-63. https://doi.org/10.1002/ajmg.1630

12. Houtenville, A., \& Kalargyrou, V. (2011) People with Disabilities. Cornell Hospitality Quarterly, 53(1), $40-52$ https://doi.org/10.1177/1938965511424151

13. Schrader, S. von, Bruyère, S., Malzer, V., \& Erickson , W. (n.d.). Absence and Disability Management Practices for an Aging ... Retrieved July 15, 2019, from http://digitalcommons.ilr.cornell.edu/cgi/viewcontent.cgi ?article $=1320 \&$ context $=$ edicollect

14. Gilbride, Dennis, Robert Stensrud, Connie Ehlers, Eric Evans, and Craig Peterson. (2000). Employers' Attitudes Toward Hiring Persons with Disabilities and Vocational Rehabilitation Services. Journal of Rehabilitation, 66(4), 17-23

15. Lengnick-Hall, M. L., Gaunt, P. M., \& Kulkarni, M. (2008). Overlooked and underutilized: People with disabilities are an untapped human resource. Human Resource Management, 47(2), 255-273. https://doi.org/10.1002/hrm.20211

16. Newton, R., Ormerod, M., \& Thomas, P. (2007). Disabled people's experiences in the workplace environment in England. Equal Opportunities International, 26(6), 610-623. https://doi.org/10.1108/02610150710777079

17. Granger, C. V. (1985). Outcome of comprehensive medical rehabilitation: An analysis based upon the impairment, disability, and handicap model. International Rehabilitation Medicine, 7(2), 45-50. https://doi.org/10.3109/03790798509166114

18. Phoenix, M., \& Rosenbaum, P. (2017). Presenting the model of risk, disability and hard-to-reach families to inform early intervention services. Disability and Rehabilitation, 41(2), 244-249. https://doi.org/10.1080/09638288.2017.1385650

19. Anand, P., \& Sevak, P. (2017). The role of workplace accommodations in the employment of people with disabilities. IZA Journal of Labor Policy, 6(1). https://doi.org/10.1186/s40173-017-0090-4

20. Louvet, E., Rohmer, O., \& Dubois, N. (2009) Social Judgment of People with a Disability in the Workplace. Swiss Journal of Psychology, 68(3), 153159. https://doi.org/10.1024/1421-0185.68.3.153

21. Hernandez, B., Mcdonald, K., Divilbiss, M., Horin, E., Velcoff, J., \& Donoso, O. (2008). Reflections from Employers on the Disabled Workforce: Focus Groups with Healthcare, Hospitality and Retail Administrators. Employee Responsibilities and Rights Journal, 20(3), 157-164. https://doi.org/10.1007/s10672-008-9063-5

22. Foster, D., \& Fosh, P. (2009). Negotiating 'Difference': Representing Disabled Employees in the British Workplace. British Journal of Industrial Relations. https://doi.org/10.1111/j.1467-8543.2009.00748.x
23. Scotch, R. K., \& McConnel, C. E. (2017, January 1). Disability and the future of work: A speculative essay. Retrieved June 15, 2019, from https://utsouthwestern.pure.elsevier.com/en/publications/ disability-and-the-future-of-work-a-speculative-essay

\section{AUTHORS PROFILE}

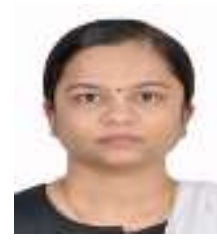

Dr.R. Mita Mehta is faculty of corporate governance and human resources management. She has more than two decades of experience in academics. She has been awarded as best HR professor by Dewang Mehta foundation in year 2012. She has published various research papers in reputed and indexed journals. She has also published two books in corporate governance.

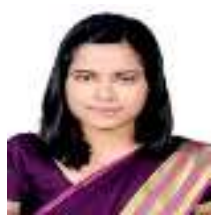

Ranu Kumari is a Marketing enthusiast who pursued her MBA from the Symbiosis International University. She had always been affected by the opportunities and freedom that the world of Business provides and currently runs her own Marketing agency. She has also been part of several social campaigns relating to women hygiene and wellness and is a person who is aware and concerned about various impending social issues. Her in-depth research abilities and sensitivity towards overlooked topics have given shape to this paper. It deals with the often ignored yet important question of whether or not the Indian corporate structure is suitable for the differently abled people

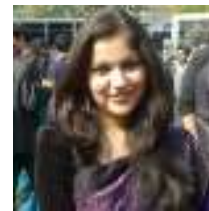

Komal Sharma has done her MBA from Symbiosis International University. She has hired for roles across Software developers such as backend developer, front-end developer, full stack developer, Devops engineer, Engineering manager, principle engineers as well as expanded our Talent Acquisition team. Built a structure around talent acquisition, onboarding, training, feedback and exit from the ground up. Daily efforts are aimed around making our culture stronger than ever along with never compromising on the quality of talent

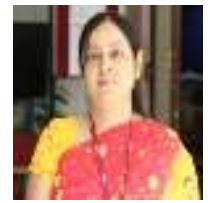

Dr. Arti Chandani, MBA (Finance) has been teaching since last 21 years in various B-school in India as well as in Brunei Darussalam. Her area of research is corporate finance, banking and corporate governance and IT. She has attended more than 50 conferences. She has written more than 30 papers in peer reviewed journals. She was awarded for Best Teacher in Financial Management by Dainik Bhaskar National Education Leadership awards. She has been organising SIMSARC (Symbiosis Institute of Management Studies-SIMS Annual Research Conference) since 2013. She has also received multiple best paper awards in conference. She is also a $\mathrm{PhD}$ supervisor in Symbiosis International (Deemed University), Pune, India. 